\title{
UMA ESTRATÉGIA DIDÁTICA NO FORMATO DE OFICINA PARA O ENSINO DO CONTEÚDO SOLUÇÕES QUÍMICAS A PARTIR DO MÉTODO COOPERATIVO DE APRENDIZAGEM JIGSAW
}

\author{
Francisca das Chagas da Silva Ferreira ${ }^{1}$, Leonardo Baltazar Cantanhede ${ }^{1}$, \\ Severina CoElho da Silva Cantanhede ${ }^{2}$ \\ ${ }^{1}$ Instituto Federal de Educação, Ciência e Tecnologia do Maranhão - IFMA, Campus de Codó \\ ${ }^{2}$ Universidade Federal do Maranhão - UFMA \\ <tchesca.ferreira@hotmail.com>,<leonardo.cantanhede@ifma.edu.br> \\ <severina.cantanhede@ufma.br>
}

DOI: $10.21439 /$ conexoes.v11i6.1094

\begin{abstract}
Resumo. Neste artigo apresentamos uma proposta de oficina para os professores de Química da educação básica, fundamentada no método Cooperativo de Aprendizagem Jigsaw. Esta abordagem tem se apresentado como um meio viável de melhoria para o ensino-aprendizagem, resolução de alguns conflitos e maior equilíbrio nas situações que promovem a competitividade no ambiente de sala de aula. Nesta perspectiva, cinco experimentos de baixo custo, fácil acesso e execução em sala de aula foram propostos para a discussão do conteúdo Soluções Químicas, abordado no ensino médio. Para tanto, disponibilizamos o plano de aula e o roteiro detalhado dos cinco experimentos, para àqueles professores que fizerem a opção por trabalhar suas aulas no formato do método Cooperativo de Aprendizagem Jigsaw.
\end{abstract}

Palavras-chaves: Ensino de Química. Aprendizagem Cooperativa. Jigsaw.

\begin{abstract}
In this paper we present a workshop proposal for Chemistry teachers of basic education based on the Cooperative Learning Method Jigsaw. This approach has been presented as a viable means of improvement for teaching and learning, resolution of some conflicts and greater equilibrium in situations that promote competitiveness in the classroom environment. In this perspective, five low cost experiments, easy access and execution in the classroom have been proposed to discuss the content Chemical Solutions, covered in high school. Therefore we have the lesson plan and the detailed roadmap of the five experiments, for those teachers who make the choice to work their classes in the Cooperative method Jigsaw Learning format.
\end{abstract}

Keywords: Chemistry teaching. Cooperative learning. Jigsaw.

\section{INTRODUÇÃO}

É consenso entre os profissionais da educação que o ensino vigente é considerado infatível e ineficiente, pois a maioria dos currículos ainda aborda em maior proporção, os conteúdos informativos, comprometendo assim a formação dos estudantes tanto como profissionais, quanto como cidadãos críticos e responsáveis perante a sociedade (SOUSA; MOITA; CARVALHO, 2011). Neste sentido, entende-se a necessidade de buscar alternativas para que o papel do professor de "ensinar coisas e soluções" seja modificado e este mesmo professor passe a "ensinar o estudante a aprender coisas e soluções" (ZUCCO; PESSINE; ANDRADE] 1999). Nesta perspectiva, o ensino da Química, segundo os Parâmetros Curriculares Nacionais para o Ensino Médio (PCNEM) também colabora com sua parcela de responsabilidade, pois sinaliza que: “o ensino da Química deve contribuir para a formação da cidadania e, dessa forma, deve permitir o desenvolvimento de conhecimentos e valores que possam servir como instrumento mediador da interação do individuo com o mundo que o cerca" (BRASIL, 1999, p. 38). 
UMA ESTRATÉGIA DIDÁTICA NO FORMATO DE OFICINA PARA O ENSINO DO CONTEÚDO SOLUÇÕES QUÍMICAS A PARTIR DO MÉTODO COOPERATIVO DE APRENDIZAGEM JIGSAW

Assim sendo, é evidente a importância do ensino a partir de novas abordagens. Neste contexto, acreditamos que a Aprendizagem Cooperativa deve ser entendida como uma proposta didática que pode contribuir como um meio de interação social e cooperação entre os estudantes (FATARELI et al., 2010). Este tipo de abordagem se diferencia das demais, por apresentar uma natureza social que possibilita o desenvolvimento de habilidades intelectuais e sociais, pois permite que os alunos possam interagir e socializar suas ideias dentro de um grupo (JOHNSON; JOHNSON; HOLUBEC, 1999 COCHITO, 2004, TEODORO et al., 2011a). Este tipo de abordagem é norteada pelas teorias do desenvolvimento cognitivo, que tem como principais defensores Piaget e Vygotsky. Segundo Piaget, a relação entre os sujeitos contribui para o desenvolvimento de conflitos cognitivos que direciona o individuo a questionar o entendimento inerente a sua própria pessoa, como também a tentativa de novos argumentos (GUEDES; BARBOSA; JOFILI, 2007). Para Vygotsky, a relação social tem significativa relevância para o aprendizado, visto que as funções mentais (compreensão, raciocínio e pensamento crítico), ditas superiores são desenvolvidas por meio da interação social e internalizadas posteriormente pelo o sujeito (CARNEIRO; LOPES, 2008).

No ensino formal, a Aprendizagem Cooperativa acontece quando todos os estudantes trabalham juntos, por meio do compartilhamento de suas atribuições específicas, em função de atingir um objetivo comum para todos (JOHNSON; JOHNSON; HOLUBEC. 1999). De acordo com especialistas, a Aprendizagem Cooperativa pode ainda contribuir para aprendizagem natural, em virtude da motivação e empenho gerado pelo trabalho em grupo. Assim, para que o trabalho cooperativo seja, de fato, significativo para o processo de ensino-aprendizagem devem estar presente alguns elementos básicos, considerados indispensáveis, para estudiosos desta abordagem (JOHNSON; JOHNSON; SMITH, 1998):

- Interdependência Positiva: cada estudante tornase responsável pela aprendizagem dos colegas, o que gera um compromisso em atingir um objetivo comum para todos;

- Responsabilidade Individual: contribui ativamente para o bom desempenho de todo o grupo, responsabilizando-se pela aprendizagem de cada estudante, como também por sua própria aprendizagem;

- Interação Face a Face: proporciona a cada estudante a oportunidade de comunicar-se com o grupo para discutir, analisar e explicar questões relacionadas ao conteúdo proposto;
- Habilidades Interpessoais: estão diretamente relacionadas com as competências inerentes de cada estudante, tais como: comunicação, senso de liderança, confiança, tomada de decisão e resolução de conflitos;

- Processamento Grupal: acompanhamento ordenado do desempenho do grupo e dos avanços relacionados à aprendizagem.

Nesta perspectiva, é importante que os professores compreendam que esses são elementos básicos e fundamentais para o desenvolvimento das competências necessárias para a organização e evolução do método cooperativo de aprendizagem, a fim de prevenir, ajustar e solucionar a possibilidade de futuros problemas (JOHNSON; JOHNSON; HOLUBEC, 1999). Assim sendo, o presente trabalho tem como objetivo apresentar uma ferramenta didática, organizada no formato de oficina e respaldada no método cooperativo de aprendizagem Jigsaw. Esta pode ser aplicada nas aulas de Química do $2^{\circ}$ ano do ensino médio, pois aborda o conteúdo Soluções Químicas que é inerente deste nível de ensino da educação básica. Para esta oficina, elaboramos cinco experimentos com a finalidade de promover, através da experimentação, uma aprendizagem mais significativa. Além disso, a proposta também estimula para a interação cooperativa e social dos estudantes. A oficina didática é sugerida para os professores de Química do ensino médio, como uma proposta que auxilia no desenvolvimento e aperfeiçoamento das atividades escolares, como também para o incentivo de uma boa convivência social em sala de aula.

\section{FUNDAMENTAÇÃO}

\subsection{Aprendizagem cooperativa e o ensino de quí- mica}

Atualmente, a comunidade escolar precisa estar atenta para os desafios de uma formação que atenda as expectativas do individuo no sentido de promover um maior comprometimento com os valores sociais, científicos e tecnológicos (BARBOSA; JÓFILI, 2004). Neste contexto, o ensino da Química tem como perspectiva contribuir e facilitar para o desenvolvimento de competências e habilidades, a partir de situações problemas reais, permitindo ao estudante interpretar, analisar dados, argumentar, avaliar e tomar decisões (BRASIL, 2007). Considerando essas necessidades formativas, torna-se evidente que o professor deve estar disponível para novos desafios que favoreçam o aperfeiçoamento de sua prática pedagógica (BARBOSA; JÓFILI, 2004). De acordo com a Lei que estabelece as Diretrizes e Bases da Educação Nacional (Lei 9.394) “a 
UMA ESTRATÉGIA DIDÁTICA NO FORMATO DE OFICINA PARA O ENSINO DO CONTEÚDO SOLUÇÕES QUÍMICAS A PARTIR DO MÉTODO COOPERATIVO DE APRENDIZAGEM JIGSAW

educação básica, tem por finalidade o pleno desenvolvimento do educando e seu preparo para o exercício da cidadania. Portanto, o currículo do ensino médio deve primar por metodologias de ensino que estimule a iniciativa dos estudantes" (BRASIL, 2014, p. 9). De fato, encontramos pesquisas que tem demonstrado as inúmeras vantagens quando se trabalha com novas metodologias. Como exemplo, destacamos a Aprendizagem Cooperativa no ensino da Química, que tem contribuído para uma melhor assimilação dos conteúdos, além de promover atitudes de cooperação e solidariedade entre os estudantes em sala de aula (FATARELI et al. 2010). Mesmo considerando esses resultados, ainda assim, no Brasil, a Aprendizagem Cooperativa é pouco explorada, sendo a Química, uma das áreas de principal destaque, que aborda o método Jigsaw como estratégia didática (TEODORO et al., 2011a). A seguir, expomos algumas das peculiaridades da Aprendizagem Cooperativa, ressaltando o método Jigsaw.

\subsection{O método jigsaw}

O Jigsaw é denominado como um método cooperativo de aprendizagem desenvolvido por Elliot Aronson et al., 1974, sendo utilizado pela primeira vez no início dos anos 70, nos Estados Unidos nas universidades do Texas e da Califórnia. Nesse processo de aprendizagem, o aluno é integrado a um grupo e junto com os colegas desenvolvem atividades específicas para um conteúdo já estabelecido pelo professor, por um determinado período de aula, buscando atingir os objetivos de uma aprendizagem mais significativa (ARONSON; PATNOE, 2011). Segundo especialistas, o método Jigsaw apresenta algumas vantagens para o desenvolvimento do ensino em ambiente de sala de aula, destacando inicialmente uma maior facilidade no entendimento do conteúdo proposto, como também uma considerável melhoria nas relações sociais desenvolvidas no ambiente escolar, pois os estudantes desenvolvem suas atividades, partindo de um objetivo comum, o que proporciona uma melhor interação entre todos os membros do grupo (ARONSON; PATNOE, 2011). Neste sentido, cada aluno é considerado como peça fundamental, visto que o funcionamento deste método é comparado a de um quebra-cabeça, pois o trabalho só é concluído quando todas as peças se encaixam, ou seja, quando todos os estudantes compreendem o conteúdo apresentado (TEODORO; QUEIROZ, 2011b).

Assim sendo, para sua aplicação, o método requer procedimentos específicos, como a organização dos grupos, que anteriormente deve ser estruturado pelo professor. Lembrando que cada grupo formado deve primar pela heterogeneidade, pois deve fomentar nos estudantes o desenvolvimento e aprimoramento de suas competências e habilidades (COCHITO, 2004). De acordo com o método a que nos referimos, os grupos são organizados e denominados de "Grupos de Base" e "Grupos de Especialistas". Nas Figura 1] e 2 a seguir, representamos o esquema estrutural de formação dos Grupos de Base e Especialistas, respectivamente:

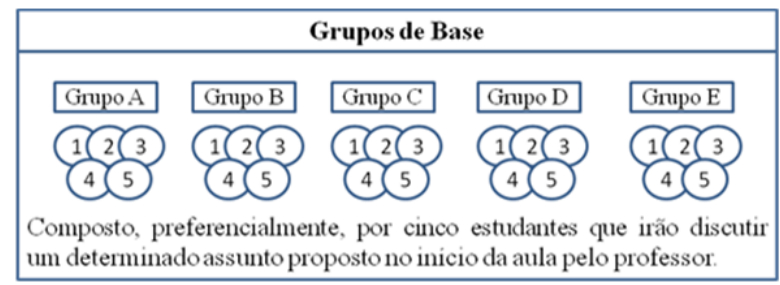

Figura 1: Representação esquemática dos Grupos de Base baseado na Aprendizagem Cooperativa, método Jigsaw.

Fonte: Adaptado do trabalho de Cochito 2004)

Nessa primeira etapa, os Grupos de Base são organizados com cinco estudantes em cada grupo. Em seguida, o professor atribui um determinado assunto que deve ser discutido por todos os estudantes.

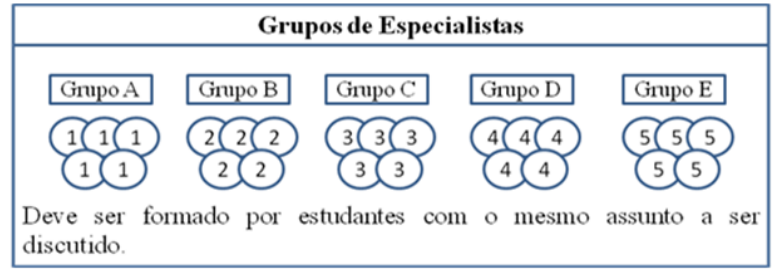

Figura 2: Representação esquemática dos Grupos de Especialistas baseado na Aprendizagem Cooperativa, método Jigsaw.

Fonte: Adaptado do trabalho de Cochito (2004)

Nos Grupos de Especialistas o assunto discutido inicialmente é desmembrado em subtópicos, considerando o número de estudantes que apresenta cada grupo. Desta forma, os alunos se tornam especialistas no conteúdo exposto, pois o método propõe discutir, esclarecer e anotar todas as dúvidas, curiosidades e principais ideias relacionadas ao tema apresentado (FATARELI et al. 2010). Na última etapa, cada aluno retorna ao seu Grupo de Base e socializa a discussão ocorrida no Grupo de Especialistas, de forma que todo o conhecimento adquirido sobre o conteúdo seja compartilhado com o Grupo de Base (TEODORO et al., 2011a, COCHITO, 2004, JOHNSON; JOHNSON; HOLUBEC, 1999). Na Figura 3, representamos o esquema estru- 
UMA ESTRATÉGIA DIDÁTICA NO FORMATO DE OFICINA PARA O ENSINO DO CONTEÚDO SOLUÇÕES QUÍMICAS A PARTIR DO MÉTODO COOPERATIVO DE APRENDIZAGEM JIGSAW

tural geral de formação dos grupos.

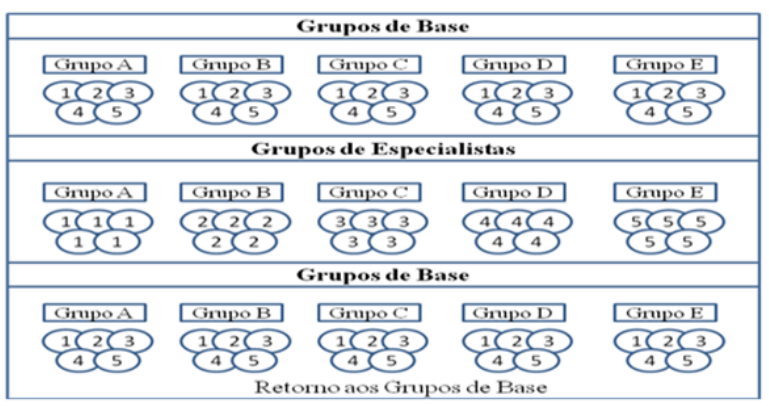

Figura 3: Representação esquemática de formação geral dos grupos baseada na Aprendizagem Cooperativa, método Jigsaw.

Fonte: Adaptado do trabalho de (COCHITO, 2004)

É importante esclarecer que é responsabilidade do professor estruturar os grupos em um momento que antecede a aplicação da proposta, lembrando que, para a formação dos Grupos de Base o professor deve considerar as habilidades de cada estudante, ou seja, as escolhas não devem ser aleatórias, visto que é primordial a colaboração de todos os participantes para um bom desempenho deste método. Assim, deve ser atribuída a cada estudante uma responsabilidade específica para desempenhar dentro do grupo. Na Figura 4 dispomos a representação dos papeis dos estudantes de acordo com o método Jigsaw.

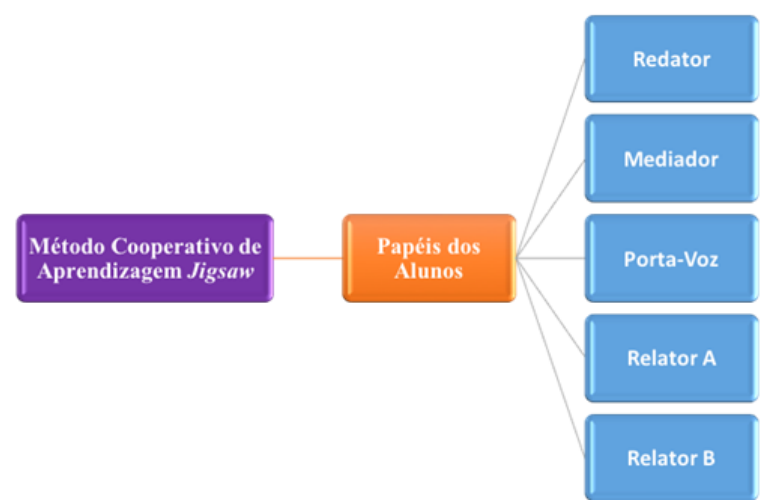

Figura 4: Representação esquemática dos papeis dos alunos no método Jigsaw.

Fonte: Elaborado pelo autor

- Redator: anota todas as conclusões do grupo, a partir da discussão dos resultados;

- Mediador: organiza as discussões de forma que todos os membros do grupo possam apresentar seus conhecimentos sobre o assunto. Também é responsável por atenuar a manifestação de possíveis divergências de opiniões dentro do grupo;

- Relator: expõe os resultados para todos os grupos. Neste caso, como o grupo é formado por cinco integrantes, o ideal é que sejam nomeados dois relatores (A e B), tendo em vista aprimorar a comunicação oral, já que esta é uma dificuldade enfrentada por muitos alunos;

- Porta-voz: único membro do grupo que tem permissão para buscar a orientação do professor quando surgem dúvidas e questionamentos.

Destacamos a importância do cumprimento de cada um destes papeis, pois um dos principais objetivos desta proposta é atribuir para cada estudante uma responsabilidade que contribua de forma positiva no desempenho da atividade, proporcionando assim uma aprendizagem mais significativa e uma melhor interação social dentro do ambiente escolar. Além disso, este formato de oficina oportuniza aos grupos, em consonância com o professor, de construírem juntos os conhecimentos, visto que o estudante não é colocado apenas como um líder ou porta voz da turma (COCHITO, 2004).

\section{METODOLOGIA}

\subsection{Planejamento da oficina}

A oficina foi elaborada considerando a abordagem do conteúdo, Soluções Químicas. O assunto foi subdividido de forma que fosse possível abordar os tipos de dispersão (suspensão, solução e dispersão coloidal), classificação das soluções a partir da natureza das partículas dispersas (solução iônica e solução molecular), solubilidade, diluição e os aspectos quantitativos das soluções (concentração comum). Justificamos a escolha de tal conteúdo em virtude da fácil execução dos experimentos, pois não é necessário o uso do laboratório, podendo ser desenvolvidos no ambiente de sala de aula. Além disso, ainda sugerimos o uso de materiais e reagentes de fácil acesso e baixo custo o que também consideramos como um ponto positivo, pois a maioria das escolas de nível médio não possuem equipamentos, materiais e reagentes em suas dependências. Na Tabela 1 . elencamos a lista de materiais e reagentes utilizados na aplicação da oficina.

É relevante destacar que, em nossa proposta de experimento, os materiais e reagentes podem ser facilmente encontrados em farmácias, supermercados e lojas de materiais de construção. Além disso, os materiais são de baixo custo, favorecendo sua aplicação nas aulas de Química. 
UMA ESTRATÉGIA DIDÁTICA NO FORMATO DE OFICINA PARA O ENSINO DO CONTEÚDO SOLUÇÕES QUÍMICAS A PARTIR DO MÉTODO COOPERATIVO DE APRENDIZAGEM JIGSAW

Tabela 1: Lista de materiais e reagentes para a oficina do conteúdo programático Soluções Químicas.

\begin{tabular}{c|c}
\hline Materiais & Reagentes \\
\hline Base de isopor & Água potável \\
\hline Copo medidor/Copo de Vidro & Álcool \\
\hline Colher de sopa & Amido de milho \\
\hline Balança de precisão & Areia \\
\hline Lâmpada de Led & Sal de cozinha (Cloreto de Sódio $-\mathrm{NaCl})$ \\
\hline Bateria de $9 \mathrm{~V}$ & Açúcar (Sacarose $\left.-\mathrm{C}_{12} \mathrm{H}_{22} \mathrm{O}_{11}\right)$ \\
\hline Fio de eletricidade & Suco artifícial em pó sabor morango e maracujá $(30 \mathrm{~g})$ \\
\hline
\end{tabular}

\subsection{Elaboração do plano de aula}

O plano de aula traduz uma sequência de ações que devem ser desempenhadas durante a aula. É a síntese de todas as etapas programadas em virtude de um período de tempo já determinado, possibilitando à interação entre professor e aluno em favor da construção de um conhecimento mais significativo (CASTRO; TUCUNDUVA; ARNS, 2008). Para o conteúdo programático Soluções Químicas, os objetivos contemplam a diferenciação dos tipos de dispersão, conceito de solução, soluto e solvente, classificação das soluções quanto à natureza das partículas dispersas e quanto à solubilidade. Também busca compreender os processos de diluição e concentração das soluções, destacando a importância das Soluções Químicas nos processos industriais e no cotidiano. Além disso, traz a indicação de algumas referências básicas, porém relevantes, que nortearão o trabalho do professor em sala de aula. A metodologia aplicada foi direcionada a partir do método Cooperativo de Aprendizagem - Jigsaw, que tem como objetivo favorecer o processo de ensino-aprendizagem e fortalecer as relações sociais no ambiente escolar (JOHNSON; JOHNSON; HOLUBEC, 1999). Na Figura 5 dispomos à representação do conteúdo programático Soluções Químicas, empregado na oficina.

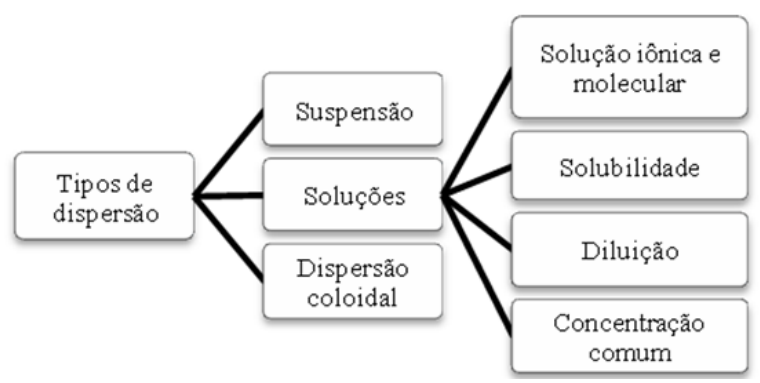

Figura 5: Representação esquemática para o desenvolvimento do conteúdo Soluções Químicas.

Fonte: Elaborado pelo autor
Considerando todas as etapas necessárias para aplicação da proposta, acreditamos ser importante esclarecer algumas questões relacionadas ao processo de avaliação em uma sala de aula cooperativa, embora esta não se diferencie muito, quando comparada com outras estratégias de ensino. Então, o processo avaliativo deve ser realizado de forma contínua, através da participação dos alunos nos grupos, por meio de relatórios e teste escrito. Portanto, cabe ao professor a escolha mais adequada para a realidade de sua sala de aula. Na Tabela 2 . sugerimos os critérios de avaliação que devem ser considerados nas aulas desenvolvidas a partir do método Jigsaw.

Considerando os critérios de pontuação descritos na Tabela 2, estabelecemos maior ou menor grau de importância para cada atividade. Justificamos a escolha das atividades com maior pontuação (Exposição oral dos alunos e Relatório final), pois a partir destas o professor tem como analisar se os estudantes alcançaram êxito na aprendizagem do conteúdo, considerando os objetivos da oficina. Na Figura 6 apresentamos o plano de aula completo para o conteúdo programático Soluções Químicas.

A aplicação dos experimentos relacionados ao conteúdo Soluções Químicas esclarece vários questionamentos, desde a concepção conceitual de uma solução, sua solubilidade, capacidade de condução de corrente elétrica, quanto alguns aspectos quantitativos como concentração e diluição. Segundo Carmo e Marcondes (2008), estudantes do ensino médio, apresentaram certa confusão no momento de conceituar os tipos de soluções. Neste contexto, acreditamos ser extremamente viável utilizar a experimentação como uma alternativa que venha contribuir para o esclarecimento dos conceitos relacionados aos conteúdos químicos, favorecendo assim a resolução de problemas e a tomada de decisão, o que torna a ação do educando mais ativa. De forma geral, concordamos com Guimarães (2009. p. 199) quando afirma que: "É necessário desafiar o 
UMA ESTRATÉGIA DIDÁTICA NO FORMATO DE OFICINA PARA O ENSINO DO CONTEÚDO SOLUÇÕES QUÍMICAS A PARTIR DO MÉTODO COOPERATIVO DE APRENDIZAGEM JIGSAW

Tabela 2: Critérios de avaliação da oficina desenvolvida a partir do método Jigsaw.

\begin{tabular}{c|c}
\hline Critérios de Avaliação & Pontuação \\
\hline Participação dos alunos na realização dos experimentos & $0,0-1,0$ \\
\hline Desenvolvimento dos papeis & $0,0-1,0$ \\
\hline Exposição oral dos alunos & $0,0-3,0$ \\
\hline Resolução das questões estabelecidas & $0,0-2,0$ \\
\hline Relatório final & $0,0-3,0$ \\
\hline
\end{tabular}

Plano de Aula

I- Dados Identificadores:

\begin{tabular}{ll}
$\begin{array}{l}\text { Instituição: } \\
\text { Série: } 2^{\circ} \text { ano do ensino médio }\end{array}$ & $\begin{array}{l}\text { Disciplina: Quimica } \\
\text { Carga Horária: } 2 \text { horas/aula }\end{array}$ \\
\hline II - Objetivos & \\
1. Diferenciar os tipos de dispersão; & \\
2. Classificar as soluções quimicas quanto à natureza das particulas dispersas e quanto à solubilidade; \\
3. Entender os processos de diluição e concentração das soluções; \\
4. Compreender a importância das soluções quimicas no cotidiano e seu emprego na indústria.
\end{tabular}

\title{
III - Conteúdo Programático
}

Soluções Quimicas

- Tipos de dispersão (suspensão, solução e dispersão coloidal);

- Classificação das soluções quanto à natureza das particulas dispersas (solução iônica e solução mol ecular);

- Solubilidade e Diluição;

- Aspectos quantitativos das soluções (concentração comum).

\begin{abstract}
IV - Metodologia
Para aplicação da proposta a aula será conduzida por meio de uma oficina experimental, na qual será utilizado o método Cooperativo de Aprendizagem - Jigsaw, apoiando-se em recursos como retro projetor (aula expositiva e dialogada), materiais e reagentes de fácil acesso e baixo custo.

V - Avaliação

O processo de avaliação será realizado, de forma continua, no decorrer de toda a proposta, considerando a participação e desempenho dos estudantes nos grupos. Também será realizado por meio de relatórios e testes escritos. As apresentações in dividuais e em grupo contribuirão para o conceito final obtido pelo estudante diante da proposta utilizada. No entanto, fica a critério do professor a escolha por uma avaliação que seja mais adequada para seu ambiente de ensino.
\end{abstract}

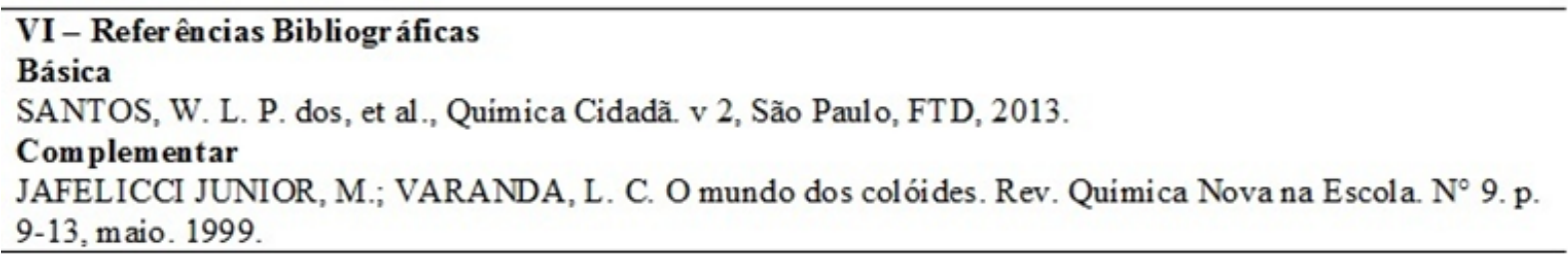

Figura 6: Plano de aula do conteúdo programático Soluções Químicas, $2^{\circ}$ ano do Ensino Médio, utilizando como estratégia didática o método Jigsaw.

Fonte: Elaborado pelo autor 
UMA ESTRATÉGIA DIDÁTICA NO FORMATO DE OFICINA PARA O ENSINO DO CONTEÚDO SOLUÇÕES QUÍMICAS A PARTIR DO MÉTODO COOPERATIVO DE APRENDIZAGEM JIGSAW

estudante, motivá-lo e ajudá-lo a superar os problemas que parecem intransponíveis; permitir a cooperação e o trabalho em grupo; avaliar não numa perspectiva de apenas dar uma nota, mas na intenção de criar ações que intervenham na aprendizagem".

\subsection{Descrição da oficina e roteiro do experimento}

A oficina foi planejada para ser aplicada em duas aulas consecutivas com duração de $50 \mathrm{~min}$. (cinquenta minutos) cada aula. Sugerimos que o número ideal de estudantes seja de 25 (vinte e cinco), pois um número maior pode afetar a qualidade do funcionamento da oficina. Considerando que algumas escolas do nível básico funcionam com um número bem maior de estudantes, recomendamos que o professor estabeleça uma divisão da turma de maneira que nenhum estudante fique de fora da oficina. Propomos ainda, que o professor que optar pela aplicação desta oficina, a estruturação dos grupos e a organização dos experimentos deve acontecer em um momento que antecede a sua execução em sala de aula. Posto isso, todas as etapas da proposta então descritas a seguir.

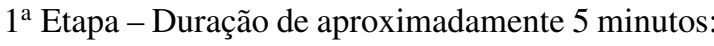
Apresentação dos grupos de base já formados anteriormente. Enfatizamos que, todos os estudantes devem ter total conhecimento do papel que irão desempenhar dentro do seu grupo;

$2^{\text {a }}$ Etapa - Duração de aproximadamente 20 minutos: O conteúdo proposto é apresentado pelo professor para toda a turma. Além disso, destaca-se a pergunta geral sobre o tema abordado, pois esta irá nortear as discussões em todos os Grupos de Base;

$3^{\text {a }}$ Etapa - Duração de aproximadamente 25 minutos: Após análise, discussão e resolução da pergunta geral proposta no início da aula, cada aluno que compõe um Grupo de Base, une-se aos demais colegas que também fazem parte dos outros grupos, na qual foi atribuído o mesmo experimento, formado assim os cinco grupos que denominamos Grupos de Especialistas. Nesta etapa, os Grupos de Especialistas irão trabalhar com o experimento específico atribuído a cada grupo, buscando esclarecer todas as dúvidas e questionamentos relacionados ao tema apresentado. Na Tabela 3 dispomos os roteiros propostos para os experimentos e que deverá ser trabalhado pelos Grupos de Especialistas, considerando o conteúdo, Soluções Químicas.

$4^{\text {a }}$ Etapa - Duração de aproximadamente 35 minutos: Nesta etapa os alunos retornam ao seu Grupo de Base para explanar a todo do seu grupo os detalhes de cada experimento que foi desenvolvido no seu Grupo de Especialistas. Finalizando todas as explicações, deta- lhadamente, sobre os procedimentos ocorridos no experimento, os estudantes retornam à discussão sobre a pergunta colocada pelo professor no início da aula. Agora com mais fundamentos sobre o tema estudado.

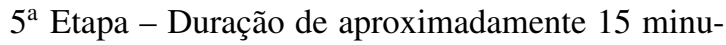
tos: Nesta etapa final, após o cumprimento dos papeis estipulados para cada estudante dentro do seu grupo, os alunos responsáveis por relatar oralmente os experimentos, apresentam para o professor e a turma, as conclusões de cada grupo.

\section{Considerações Finais}

Considerando a Química que é ensinada atualmente na maioria das escolas públicas e privada de nível médio, chegamos à conclusão de que esta disciplina muito se resume a cálculos matemáticos, fórmulas e nomenclaturas de compostos que necessitam ser memorizadas. Poucas escolas têm como hábito utilizar a experimentação como complemento de suas aulas expositivas, e quando utilizam, não conseguem envolver ativamente os estudantes, pois apenas sugere o cumprimento de roteiros pré-estabelecidos, o que descarta o caráter investigativo e a possibilidade de tentar relacionar os conceitos trabalhados a partir do experimento que está sendo desenvolvido (KASSEBOEHMER; FERREIRA. 2009). Este fato nos remete a falta de contextualização da disciplina, o que consideramos como uma das possíveis causas do alto nível de rejeição dos alunos em estudar essa ciência, além disso, também compromete o processo de ensino-aprendizagem. De acordo com Vygotsky (2000), "o ensino direto de conceitos é impossível e infrutífero. Quando não se procura articular conceitos científicos ao cotidiano, os conceitos científicos permanecem isolados no plano formal e abstrato".

Neste contexto, pensar o ensino de forma mais prática, não impossibilita que o estudante possa trabalhar questões tradicionais da Química, especialmente se essas questões forem estruturadas de forma que seja possível considerar a capacidade de desenvolver os conceitos e não apenas seguir roteiros prontos, memorizar fórmulas e fatos (FERREIRA; HARTWIG; OLIVEIRA. 2010)). Assim, na tentativa de implementar um ensino de melhor qualidade, consideramos a necessidade do professor se envolver em práticas que o ajudem a melhor desenvolver seu trabalho em sala de aula. Este fato, justifica a nossa escolha em trabalhar com o método Jigsaw, pois este método tem apresentado resultados satisfatórios para a melhoria do processo de ensinoaprendizagem e também contribuído para as relações sociais positivas em ambiente escolar (TEODORO et al., 2011a). Quanto ao ensino de Química, pesquisas 
Tabela 3: Roteiro dos experimentos sobre o conteúdo programático Soluções Químicas a serem desenvolvidos nos Grupos de Especialistas.

\begin{tabular}{|c|c|}
\hline $\begin{array}{l}\text { Soluções } \\
\text { Químicas }\end{array}$ & Procedimento \\
\hline $\begin{array}{l}\text { Tipo de } \\
\text { Dispersão }\end{array}$ & $\begin{array}{l}\text { Solução: Em um copo de vidro, colocar água até a metade do copo, em seguida } \\
\text { adicionar álcool. } \\
\text { Dispersão coloidal: Em um recipiente pequeno de vidro, colocar o amido de milho e } \\
\text { adicionar água aos poucos e com o auxílio de uma colher mexer a mistura até parecer } \\
\text { homogênea. } \\
\text { Suspensão: Em um copo de vidro, colocar água e adicionar areia peneirada. } \\
\text { Observar e anotar (nos três casos) o que acontece e responder: Como ocorre cada } \\
\text { tipo de dispersão? }\end{array}$ \\
\hline $\begin{array}{l}\text { Solução } \\
\text { iônica e } \\
\text { molecular }\end{array}$ & $\begin{array}{l}\text { Solução Iônica: Em um copo de vidro, colocar } 150 \mathrm{ml} \text { de água e adicionar uma colher } \\
\text { de chá de sal (cloreto de sódio). } \\
\text { Solução Molecular: Em um copo de vidro colocar } 150 \mathrm{ml} \text { de água e adicionar uma } \\
\text { colher de chá de açúcar (sacarose). } \\
\text { Condutividade Elétrica: A uma lâmpada de led, amarrar dois fios e encaixar numa } \\
\text { base de isopor. Prender as pontas dos fios em uma bateria de } 9 \mathrm{~V} \text { e cortar um dos fios. } \\
\text { Em seguida, coloca as pontas dos fios (cortados) dentro das duas soluções (iônica e } \\
\text { molecular) e verificar a capacidade de condução de corrente elétrica das soluções. } \\
\text { Observar e anotar o que ocorre e responder: Qual a diferença entre uma solução } \\
\text { iônica e molecular? }\end{array}$ \\
\hline Solubilidade & $\begin{array}{l}\text { Em uma balança de precisão, pesar } 25 \mathrm{~g}, 10 \mathrm{~g} \mathrm{e} 5 \mathrm{~g} \text { de suco artificial em pó sabor } \\
\text { maracujá. Em seguida, colocar no primeiro copo de vidro } 25 \mathrm{~g} \text { de suco em pó, no } \\
\text { segundo copo } 10 \mathrm{~g} \text { e no terceiro copo } 5 \mathrm{~g} \text {. Adicione em cada um dos copos } 200 \mathrm{~mL} \text { de } \\
\text { água. Observar, anotar o que ocorre e responder: } 0 \text { que influencia na solubilidade } \\
\text { de uma solução? }\end{array}$ \\
\hline Diluição & $\begin{array}{l}\text { Em um copo de vidro colocar } 200 \mathrm{~mL} \text { de água, adicionar } 10 \mathrm{~g} \text { de suco artificial em pó } \\
\text { sabor morango e misturar com um auxilio de uma colher. Em outro copo de vidro, } \\
\text { colocar metade da solução anterior e adicionar } 100 \mathrm{~mL} \text { de água. Em um terceiro copo } \\
\text { de vidro, colocar metade da solução do segundo copo e adicionar } 50 \mathrm{~mL} \text { de água. } \\
\text { Observar, anotar o que acontece e responder: Como ocorre o processo de diluição } \\
\text { das soluções e qual a importância da diluição nas concentrações químicas? }\end{array}$ \\
\hline $\begin{array}{l}\text { Concentração } \\
\text { Comum }\end{array}$ & $\begin{array}{l}\text { Em dois copos de vidro colocar } 100 \mathrm{~mL} \text { de água. Em seguida, enumerar os copos (1 e } \\
\text { 2). Com o auxílio de uma colher de sopa adicionar no copo } 1 \text { uma colher de sal de } \\
\text { cozinha (Cloreto de sódio) e no copo } 2 \text { duas colheres de sal de cozinha (Cloreto de } \\
\text { sódio). Observar, anotar o que ocorre e responder: Explique a diferença entre as } \\
\text { duas soluçóes em termos de concentração? }\end{array}$ \\
\hline
\end{tabular}


UMA ESTRATÉGIA DIDÁTICA NO FORMATO DE OFICINA PARA O ENSINO DO CONTEÚDO SOLUÇÕES QUÍMICAS A PARTIR DO MÉTODO COOPERATIVO DE APRENDIZAGEM JIGSAW

demonstram que o método Jigsaw vem contribuindo para o desenvolvimento ou/e aperfeiçoamento de habilidades básicas como, melhor rendimento escolar, negociação de significados, apropriação de competências sociais e cooperação entre os estudantes em sala de aula (FATARELI et al., 2010).

Investigações que tratam da utilização do método Cooperativo de Aprendizagem - Jigsaw, na educação básica, tem demonstrado que existe um quantitativo bastante resumido de publicações nesta área (TEODORO; QUEIROZ, 2011b). Desta forma, consideramos a necessidade de disponibilizar para o professor de Química da educação básica, novos métodos que possam despertar e motivar os estudantes para o interesse cooperativo no ambiente escolar, pois esta prática pode favorecer uma aprendizagem mais significativa e prazerosa (FATARELI et al. 2010).

Considerando o exposto, entendemos que a aplicação da oficina tem como contribuir tanto para aprendizagem dos conteúdos químicos abordados a partir da experimentação, quanto promover o desenvolvimento de algumas habilidades como leitura, escrita, argumentação e tomada de decisão. Destacamos ainda, que a proposta viabiliza ao professor desenvolver o seu trabalho em um formato diferenciado dos padrões do ensino tradicional, permitindo ao aluno participar da aula de forma mais atuante. Assim, concluímos que, diferentemente da proposta tradicional, a Abordagem Cooperativa coaduna com as indicações sugeridas nos $\mathrm{Pa}$ râmetros Curriculares Nacionais para o Ensino Médio, quando descreve que: "A educação atual exige métodos de aprendizagem compatíveis, ou seja, condições efetivas para que os alunos possam participar de um convívio social que lhe dê tomar gosto pelo conhecimento" (BRASIL, 2007, p. 9).

\section{REFERÊNCIAS}

ARONSON, E.; PATNOE, S. Cooperation in the classroom: The jigsaw method. 3. ed. London: Pinter \& Martin Ltd., 2011.

BARBOSA, R. M. N.; JÓFILI, Z. M. S. Aprendizagem cooperativa e ensino de química: parceria que dá certo. Rev. Ciência \& Educação, v. 10, n. 1, p. 55-61, Jan. 2004.

BRASIL. Ministério da educação. secretaria de educação média e tecnologia. parâmetros curriculares nacionais para o ensino médio. ciências da natureza, matemática e suas tecnologias. Brasília, DF, 1999.
. Ministério da educação. parâmetros curriculares nacionais $(\mathrm{pcn}+)$. ciências da natureza, matemática e suas tecnologias. Brasília, 2007. Disponível em: <http://portal.mec.gov.br/seb/arquivos/pdf/ CienciasNatureza.pdf.> Acesso em: 01/11/2014.

[lei darcy ribeiro (1996)]. ldb: lei de diretrizes e bases da educação nacional [recurso eletrônico]: lei $\mathrm{n}^{\mathrm{o}}$ 9.394, de 20 de dezembro de 1996, que estabelece as diretrizes e bases da educação nacional. Brasília: Câmara dos Deputados, Edições Câmara, 2014.

CARMO, M. P. d.; MARCONDES, M. E. R. Abordando soluções em sala de aula-uma experiência de ensino a partir das ideias dos alunos. Rev. Química Nova na Escola, n. 28, p. 37-41, maio. 2008.

CARNEIRO, E. B.; LOPES, M. C. Aprendizagem cooperativa no ensino de química: aplicação na disciplina de química geral. In: XIV ENEQ, 2008, Anais. [S.1.]: Curitiba, PR., 2008.

CASTRO, P.; TUCUNDUVA, C. C.; ARNS, E. M. A importância do planejamento das aulas para organização do trabalho do professor em sua prática docente. Rev. Cientıfica de Educaçao, v. 10, n. 10, p. 49-62, jan/jun 2008.

COCHITO, M. Cooperação e aprendizagem: educação intercultural. Lisboa: Acime, 2004.

FATARELI, E. F.; FERREIRA, L. d. A.; FERREIRA, J. Q.; QUEIROZ, S. L. Método cooperativo de aprendizagem jigsaw no ensino de cinética química.

Rev. Química nova na escola, v. 32, n. 3, p. 161-168, Agosto 2010.

FERREIRA, L. H.; HARTWIG, D. R.; OLIVEIRA, R. d. Ensino experimental de química: uma abordagem investigativa contextualizada. Rev. Química Nova na Escola, v. 32, n. 2, 2010.

GUEDES, M. G. M.; BARBOSA, R. M. N.; JOFILI, Z. M. S. Aprender ciências em grupo: o que os alunos pensam? In: VI Encontro Nacional de Pesquisa em Educação em Ciências, 2007, Florianópolis, SC.

Anais... [S.1.]: Universidade Federal de Santa Catarina. Florianópolis, SC: Associação Brasileira de Pesquisa em educação em ciências, 2007. p. 865-878.

GUIMARÃES, C. C. Experimentação no ensino de química: caminhos e descaminhos rumo à aprendizagem significativa. Rev. Química nova na escola, v. 31, n. 3, p. 198-202, 2009. 
UMA ESTRATÉGIA DIDÁTICA NO FORMATO DE OFICINA PARA O ENSINO DO CONTEÚDO SOLUÇÕES QUÍMICAS A PARTIR DO MÉTODO COOPERATIVO DE APRENDIZAGEM JIGSAW

JOHNSON, D. W.; JOHNSON, R. T.; HOLUBEC,

E. J. Los nuevos círculos del aprendizaje. La

cooperación en el aula y la escuela. [S.1.]: Virginia:

Aique, 1999.

JOHNSON, D. W.; JOHNSON, R. T.; SMITH, K. A. A

aprendizagem cooperativa retorna às faculdades: qual

é a evidência de que funciona? In Change, v. 30, n. 4,

p. 26, julho/agosto 1998.

KASSEBOEHMER, M. A. C.; FERREIRA, L. H.

Aproximações ao modo de produção da ciência:

Propostas de problematização nos livros didáticos

de química. In: Atas do VII Encontro Nacional

de Pesquisa em Educação em Ciências. [S.1.]:

Florianópolis, SC, 2009.

SOUSA, R. P. d.; MOITA, F. d.; CARVALHO, A.

B. G. Tecnologias digitais na educação. Campina

Grande-PB, Eduepb, 2011.

TEODORO, D. L. et al. Formação docente no ensino superior de química: contribuições dos programas de aperfeiçoamento de ensino. Rev. Química Nova, v. 34 n. 4, p. 714-719, fev 2011a.

TEODORO, D. L.; QUEIROZ, S. L. Panorama das pesquisas sobre aprendizagem cooperativa no ensino de ciências. In: VIII Encontro Nacional de Pesquisa em Educação em Ciências, 2011, Campinas, SP. Anais. [S.l.]: Universidade Estadual de Campinas, 2011b.

VYGOTSKY, L. S. A formação social da mente: o desenvolvimento dos processos psicológicos superiores. São Paulo: Martins Fontes, 2000.

ZUCCO, C.; PESSINE, F. B.; ANDRADE, J. B. d. Diretrizes curriculares para os cursos de química. Rev. Química Nova, v. 22, n. 3, 1999. 